Royal Netherlands Institute for Sea Research

This is a postprint of:

Lavaleye, M.; Duineveld, G.; Bergman, M. \& van den Beld, I. (2017). Long-term baited lander experiments at a cold-water coral community on Galway Mound (Belgica Mound Province, NE Atlantic). Deep-Sea Research, Part II. Topical Studies in Oceanography, 145, 22-32

Published version: https://dx.doi.org/10.1016/i.dsr2.2015.12.014

Link NIOZ Repository: www.vliz.be/imis?module=ref\&refid=291231

[Article begins on next page]

The NIOZ Repository gives free access to the digital collection of the work of the Royal Netherlands Institute for Sea Research. This archive is managed according to the principles of the Open Access Movement, and the Open Archive Initiative. Each publication should be cited to its original source - please use the reference as presented.

When using parts of, or whole publications in your own work, permission from the author(s) or copyright holder(s) is always needed. 


\title{
Long-term baited lander experiments at a cold-water coral community on Galway Mound (Belgica Mound Province, NE Atlantic)
}

\author{
Marc Lavaleye ${ }^{\mathrm{a}^{*}}$, Gerard Duineveld ${ }^{\mathrm{a}}$, Magda Bergman ${ }^{\mathrm{a}}$, Inge van den Beld ${ }^{\mathrm{b}}$ \\ ${ }^{a}$ Royal Netherlands Institute for Sea Research, P.O. Box 59, 1790AB Den Burg, Texel, The Netherlands \\ b IFREMER DEEP/LEP (Laboratoire Environnement Profond), BP 70, 29280 Plouzané, France \\ * Corresponding author. E-mail address: Marc.Lavaleye@nioz.nl (M. Lavaleye).
}

Available online 23 December 2015

http://dx.doi.org/10.1016/j.dsr2.2015.12.014

Keywords:

Baited camera

Cold-watercorals

Deep-sea scavengers

Temporalpatterns

\begin{abstract}
A long-term lander employing a baited camera system was developed to study temporal variation in the presence of scavenging fish and invertebrates at a cold-water coral community on Galway Mound (Belgica Mound Province, NE Atlantic). The camera system was tested during two successful long-term deployments for periods of 6 and 12 months respectively. The baited system consisting of two separate video cameras with infrared lights and a bait dispenser with 24 bait positions, recorded more than 15,500 clips of $17 \mathrm{~s}$, regularly spread over both periods. New bait, consisting of sardines in oil, was offered at regular time intervals, and attracted scavengers over the whole period of deployment, and especially the crab Chaceon affinis did still eat from it till the end of the deployments. However, the attractiveness for some scavengers, i.e. amphipods, diminished quite quickly. In addition to invertebrate scavengers, namely $C$. affinis, two other crab species, amphipods, a shrimp and a starfish, also 7 species of fish were recorded near the bait, of which Lepidion eques was by far the most common. Though there was no concrete evidence for seasonal patterns, the observations showed substantial temporal variation in the abundance of several species, especially the crabs $C$. affinis and Bathynectes maravigna and the fish Phycis blennoides. It is concluded that longterm deployments of such a baited camera system can produce novel data. For instance such a system could be employed for monitoring impacts of disturbances on the deep-sea floor (e.g. mining), as we infer that mobile scavengers will be among the first organisms to show a visible reaction to any chemically and physically (noise, vibrations) alteration of the environment similar to a mine canary.
\end{abstract}

\section{Introduction}

Benthic communities dominated by colonial coldwater corals (CWC) have been found worldwide from depths of $\sim 100$ to more than $1000 \mathrm{~m}$, on continental shelves, slopes, deep-sea canyons and seamounts (Davies and Guinotte, 2011). The 3D structure and complexity provided by the coral framework has an important effect on the composition and abundance of the associated fauna (Buhl-Mortensen et al., 2010). Indeed studies have shown that such communities may become hotspots of benthic activity (van Oevelen et al., 2009), biomass and biodiversity (Henry and Roberts, 2007). Video observations made in CWC reefs along the Norwegian margin and in deep-water W of Ireland showed a large variety and abundance of fish (Costello et al., 2005) pointing to importance of CWC as feeding, hiding or nursery habitat for fish. Subsequent studies showed this to be true in many of the areas studied ( $\mathrm{D}$ 'Onghia et al., 2010; Söffker et al., 2011; Purser et al., 2013; Kutti et al., 2014) though it is not entirely clear whether the fish distribution is simply a function of complex topography or presence of corals (Auster, 2005,; D 'Onghia et al., 2012).

Most observations on fish and megafauna in CWC and other deep-sea habitats come from ROV or tethered camera recordings made during cruises of opportunity (Costello et al., 2005). There is little insight in responses of higher trophic levels to intra- and interannual variation in productivity, near bed particle flux and current regime as observed in NE Atlantic CWC (Duineveld et al., 2007) and abyssal habitats (Witbaard et al., 2001; Billett et al., 2010) and elsewhere (e.g. Ruhl and Smith, 2004). First attempts to obtain long-term high-frequency time-series observations of deep-sea scavenging demersal fish and crustaceans in the Atlantic were made by Kemp et al. (2008) who deployed a benthic lander (DOBO) equipped with still camera and multiple bait release in the deep Atlantic for a period of 38 days. Prior to the Kemp et al. (2008)'s 's study, baited deployments cameras had been widely used in short term studies of abundance, species composition or behaviour of scavengers in the deep sea (review King et al., 2007). Another application of long-term visual observations in the deep-sea with a relatively long history consists of monitoring the community ecology of scavengers on large food falls like whale carcasses (Smith et al., 2015). Latter studies are not so much designed to study the seasonality of scavengers, but more to follow the degradations of the carcass and the changes this imposes on the community living on the carcass. Also in shallow water habitats such as tropical coral reefs where fish 
cannot be extracted, baited cameras are more frequently being used for this purpose (e.g. Martinez et al., 2011,; Merritt et al., 2011,; Dunlop, 2013). Recently long term moored cameras attached to non-baited cabled observatories in the deep Pacific have allowed detailed analysis of behavioural patterns of invertebrates and fish on time scales varying from hours to months in relation to environmental variables (Doya et al., 2014; Matabos et al., 2014).

Obtaining long-term visual records of scavengers with a baited camera involves several technical issues one of the most important being preservation of bait over longer periods. However data storage capacity for imagery, electrical energy and means of illumination are also important considerations. In this study we describe a long-term baited camera system with regular new bait exposures in time, and results of its deployments in a CWC community. The deployments had a total duration of 18 months and consisted of 2 periods between 2010 and 2012. The deployment site was at 784 $m$ depth on Galway Mound located in the Belgica Mound Province (W of Ireland) being one of the mounds with a dense cover of live cold-water corals (Foubert et al., 2005). The study was part of the EU-project CoralFISH concerned with the interaction between fish, fisheries and cold water coral habitat. The objectives of our study were firstly to test the design and secondly resolve any temporal variation in the presence of scavenging fish and invertebrates within the local CWC community.

\section{Material and methods}

\subsection{Baited video system}

The baited video system that we used was partly custom made at NIOZ and consists of a High-Definition (HD) videocamera, strobe, visible light and infrared illumination, and a bait dispenser. The HD camera is a consumer Sony ${ }^{\mathrm{TM}}$ HDRSR12E handycam built into a titanium housing (grade-5) with an acrylic window rated to $6000 \mathrm{~m}$ water depth (Fig. 1A). The camera has an internal $120 \mathrm{~GB}$ hard drive for HD video and still image storage. An embedded control board, with RS232 port, provides functionality for stand-alone deployments including timelapse video imaging and still photography or a combination of both. The digital HD-video and still images can be retrieved from the camera with a USB2.0 connection without opening the underwater housing. The camera has connections and control over two external light sources and an external high speed TTL strobe (250J) (Fig. 1A). Power for camera, lights or strobe is supplied by an external source which in this case consisted of a glass Benthos ${ }^{\mathrm{TM}}$ sphere containing series of Li batteries (total $300 \mathrm{Ah}$ ) and controller hardware.

For the experiments performed in this study we used the HD videocamera in combination with a custom-made infrared (IR) high output light source (Fig. 1B and C). The housing of the IR light is made of Delrin with an acrylic window and sandwiched aluminium-titanium cooling ribs. The housing is filled with fluorinert $\left(3 \mathrm{M}^{\mathrm{TM}}\right)$ and pressure compensated by a flexible membrane. The IR light contains two power illuminators assembled with a total of 60 high efficiency AIGaAs diode chips per illuminator. The peak wavelength is $735 \mathrm{~nm}$. The thermal management circuitry also allows the light to be used in air. As a bait dispenser we used a 24 vial carousel belonging to a PPS 4/3 Technicap ${ }^{\mathrm{TM}}$ sediment trap (Fig. 2). Carousel and motor were mounted in a custom-made frame. The vials on the carousel were filled with sardines in oil purchased in the supermarket, with the idea that the oil would preserve the sardines over a one year deployment. Each vial contained approximately $230 \mathrm{~g}$ of sardine meat. One or two separate cameras systems, with their own infrared lights and batteries, and bait dispenser were mounted on a benthic lander (Fig. 2). This so-called ALBEX lander consists of an aluminium frame with Benthos ${ }^{\mathrm{TM}}$ floats and dual Benthos ${ }^{\mathrm{TM}}$ releasers and $250 \mathrm{~kg}$ single ballast. Additional equipment on the lander comprised a PPS 4/3 Technicap $^{\mathrm{TM}}$ sediment trap with 12 vials, a Nortek ${ }^{\mathrm{TM}}$ Aquadopp current meter, a Wetlabs ${ }^{\mathrm{TM}}$ FLNTU combined turbidity (optical backscatter-OBS) and fluorescence (chlorophyll sensitive) sensor, and radio plus satellite beacon for retrieval.

\subsection{Deployments}

Before assemblage of the camera, illumination and bait system shown in Fig. 1, we made a small pilot study to test the capabilities of available cameras and of the effects of different light sources on the attraction of bathyal scavengers. Previous studies (e.g. Widder et al., 2005,; Raymond and Widder, 2007,; Chidami et al., 2007) had shown that white light may repel fish in a baited camera set-up and instead of white light, far red or infrared (IR) light were proposed. The illumination test deployments took place in July 2008 during RV Pelagia cruise 64PE292 on Hatton Bank (58 $\left.44.05^{\prime} \mathrm{N} 18^{\circ} 43.39 \mathrm{~W}\right)$ at $840 \mathrm{~m}$ depth. The site is characterized by concentrations of cold-water corals on protruding low knolls. For this pilot we used the lander shown in Fig. 2 rigged with a Sony ${ }^{\text {TM }}$ HDR-SR8E camera in a provisional housing, a 12 vial Technicap bait dispenser with sardines in oil as bait, a white light source (Deep-Sea Power \& Light $^{\mathrm{TM}} 50 \mathrm{~W}$ LED) and a Kongsberg $^{\mathrm{TM}}$ infrared light source $(735 \mathrm{~nm})$ owned by SAMS (Oban, Scotland). During the first illumination test deployment a bait was exposed and filmed for $5 \mathrm{~h}$ while illuminated with white light followed $24 \mathrm{~h}$ later by another bait exposure of $5 \mathrm{~h}$ illuminated with IR light. In the second illumination test deployment two baits were exposed with $24 \mathrm{~h}$ interval but both exposures were filmed with white and IR lights alternatingly illuminating the scene for $15 \mathrm{~min}$. This was done to observe actual responses of fish to changes in light condition (Raymond and Widder 2007). The third and last short illumination test deployment was a duplication of the two former i.e. bait was exposed twice and filmed with either white or IR light followed by bait exposure where the scene was alternatingly illuminated by white and IR light.
(A)

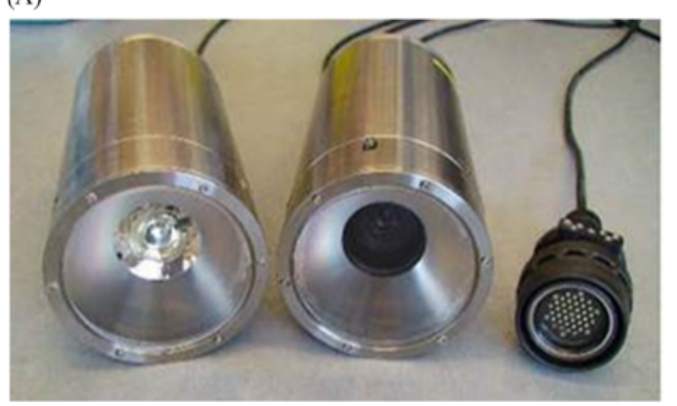

(B)

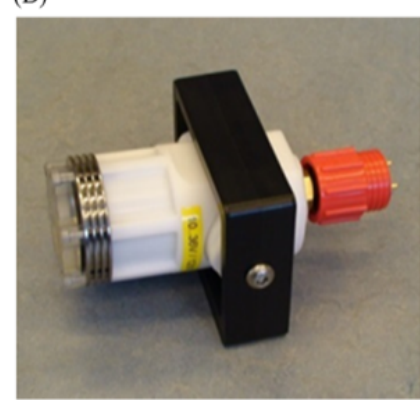

(C)

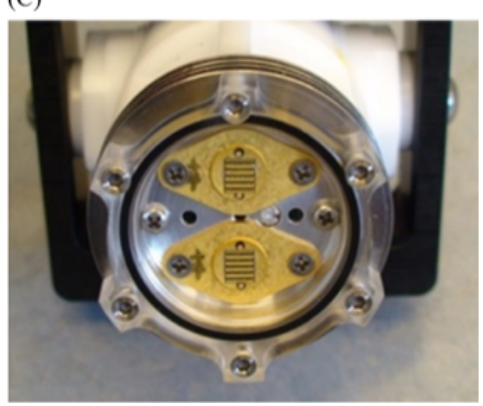

Fig. 1 UW video camera and.lights. (A) Strobe, HD video camera and LED visible light, (B) infra-red Led light manufactured by NIOZ, and (C) detail of infra-red Led lights 
(A)

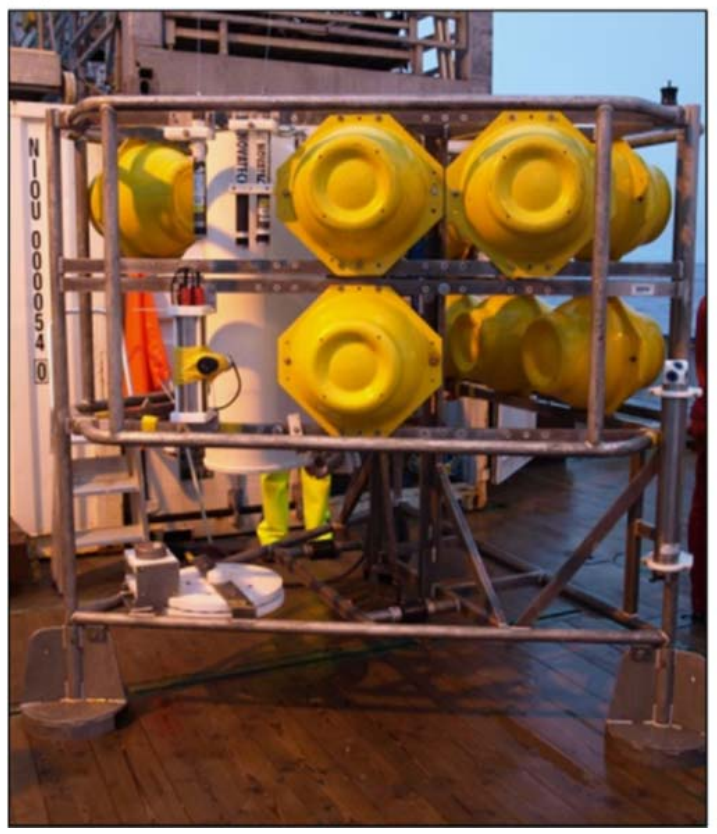

(B)

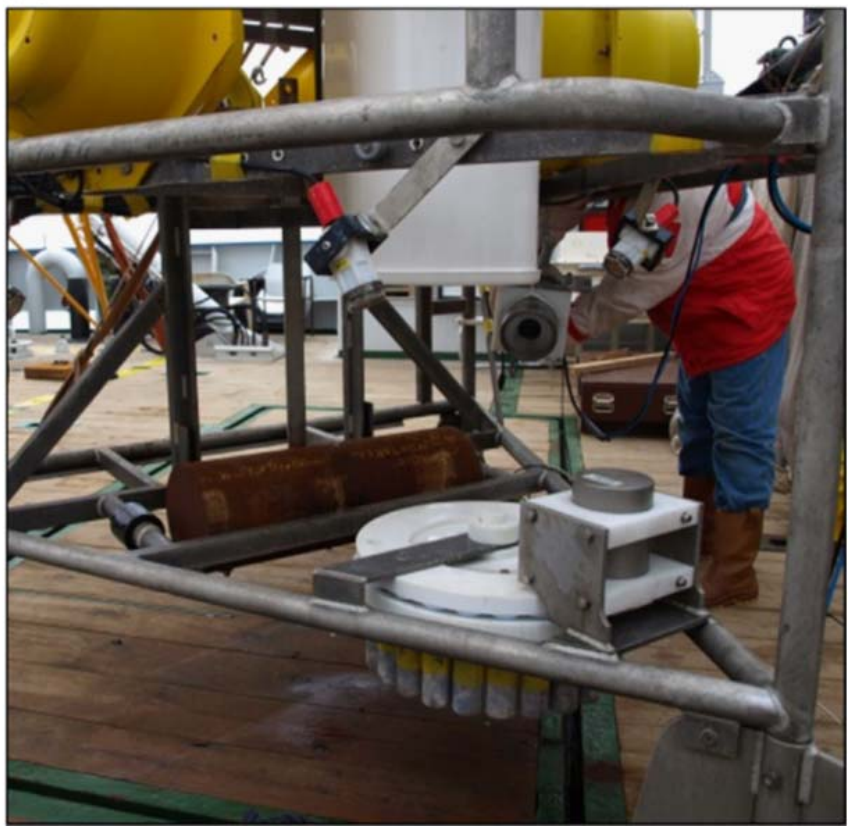

Fig. 2 (A) Benthic lander (ALBEX) with bait dispenser in left hand corner. (B) Detail bait dispenser with InfraRed LED lights and camera.

During the EU-CoralFISH project (2009-2013) the video-system was used in three one-year deployments on Galway Mound (Porcupine Seabight, W Ireland, Fig. 3). The position on Galway Mound was $51^{\circ} 27.1^{\prime} \mathrm{N}-$ $11^{\circ} 45.14 \mathrm{~W}$ at 784 water depth. On its first long-term deployment in October 2009 the battery pack failed and no images were recorded. The second long-term deployment was done at the same position and started on 21 September 2010. To decrease the risk of another camera failure and increase the number of video clips two independently working cameras with $\mathrm{IR}$ lights had been mounted on the lander during this second long-term deployment, both filming in turns the same bait but from different angles. In the bait dispenser every second position was left open (no bait) to enhance contrast with exposure of bait. As a result vials with bait were open for 10 days contrasting with 18 day periods without bait. The cameras were each programmed to record clips of $17 \mathrm{sec}$ duration every hour with a 30 min delay between cameras. This second long-term deployment was broken off prematurely on 8 July 2011 due to a failing acoustic releaser which caused the lander to rise to the surface. The lander was safely salvaged without damage by the Irish fishing vessel Fiona K II from Dingle, and after inspection it was found out that all equipment had worked properly. Though the cameras still worked during retrieval, the maximum memory storage had been reached much earlier than calculated, i.e. on 20 March 2011 when the 7th baited vial was exposed for three days. This means that the video recordings after 20 March were not stored, and thus lost. In all, this deployment yielded a total of 7996 video clips (3998 clips per camera) over a period of 178 days, resulting on average in 45 video clips per day.

The third long-term deployment of the camera system on Galway Mound started on 4 October 2011 and lasted until 5 October 2012 when the lander was retrieved as scheduled. Also during this deployment two cameras with IR lights were mounted on the lander programmed to record alternatingly. In contrast to the second deployment each cameras recorded a video clip of $17 \mathrm{~s}$ length every 2 h12 min in order to have full coverage of the deployment period. The second camera had a $1 \mathrm{~h} 06$ min delay with the first camera so that the combined result would give a video clip every $1 \mathrm{~h} 06 \mathrm{~min}$. A first inspection of data from the second deployment showed that a few days after first exposure the bait appeared to have lost its attraction especially so for scavenging amphipods. On this basis we made the choice of filling up the open spaces in the bait carousel to record more bait exposures, meaning that all 24 positions of the bait dispenser had a vial filled with bait. Every 15 days a new vial with bait was opened, and the old bait vial closed. Coincidentally two vials (number 4 and 5 ) were lost from the bait dispenser while deploying the lander due to the heavy swell. These positions thus mark absence of bait. A total of 7513 video clips were recorded by the cameras with in most cases equal intervals over the whole year.

\section{Results and discussion}

\subsection{Illumination test deployments (Hatton Bank 2008)}

Differences in behaviour of fish under white light versus infrared light conditions are illustrated by calculating the time that a species was visible on the video as a percentage of the total recording time with that particular light source. These percentages were plotted for each species and each light source separately in Fig. 4. The results in Fig. 4 indicate that some species were recorded over longer periods under a certain light condition. This is most evident with the North-Atlantic codling Lepidion eques which was recorded for relatively longer time periods when white light was used. This is in contrast with Trenkel et al. (2004) who found that $L$. eques avoids the white lights of an ROV. Also Synaphobranchus kaupii and Molva dypterygia spent relatively longer periods in view of the camera with white light. The opposite was seen with the tusk Brosme brosme which was only seen when infrared light was used though the average time it spent in the view of the camera was overall short. Observations on the behaviour of the fish indicate that both $L$. eques and $M$. moro spent more time actively swimming and exploring the bait in infrared light than in white light. On basis of these results and evidence from literature mentioned above that white light may bias results of baited video experiments, we pursued with manufacturing our own IR led lights and these were the only lights used during the following deployments. 


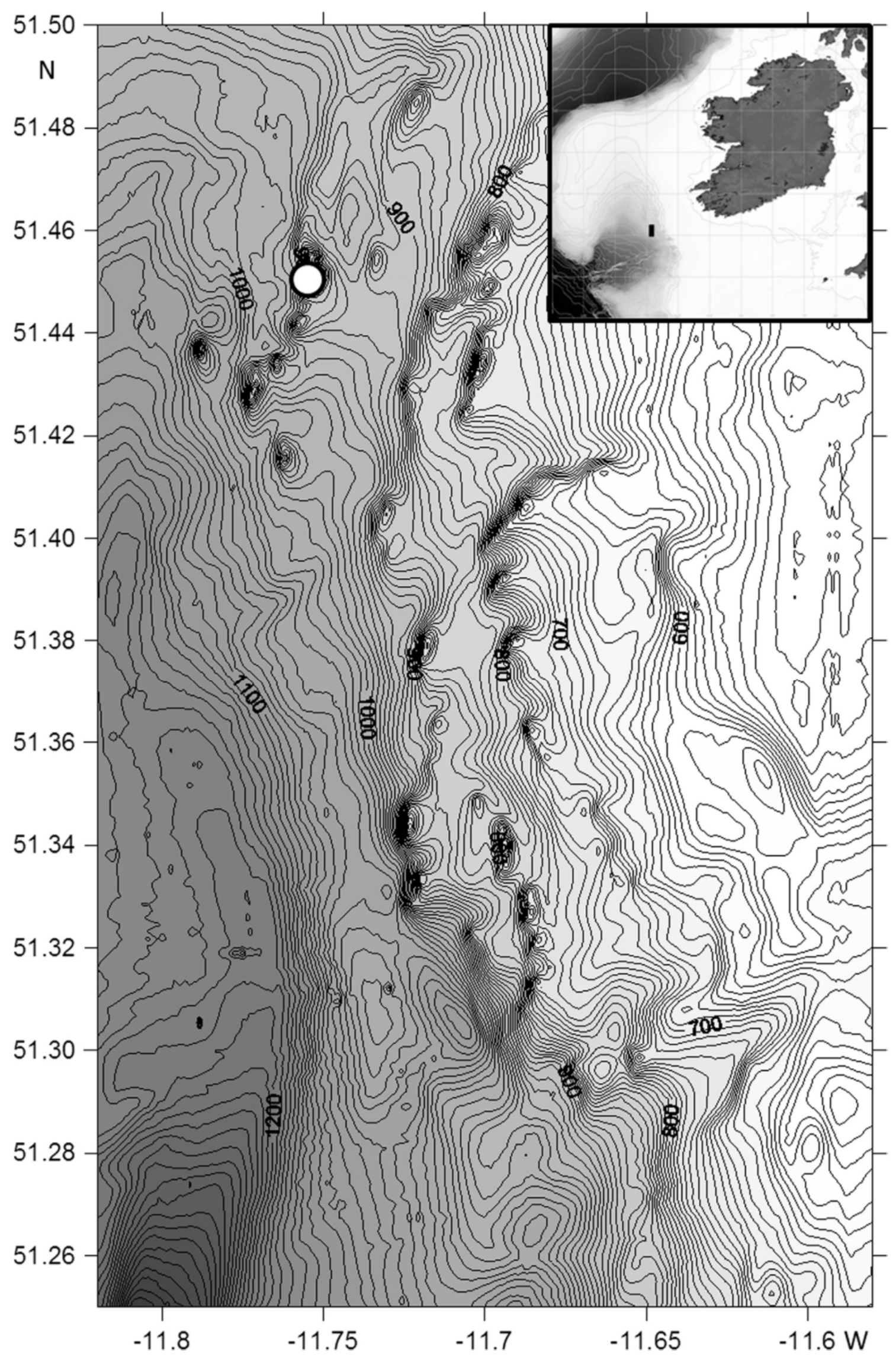

Fig. 3 Detailed bathymetry of the Belgica Mound Province with scattered mounds protruding from the seafloor. Galway Mound has been marked with a white dot. Inset: Ireland and the Porcupine Seabight, with the Belgica Mound Province indicated as a black rectangle. 


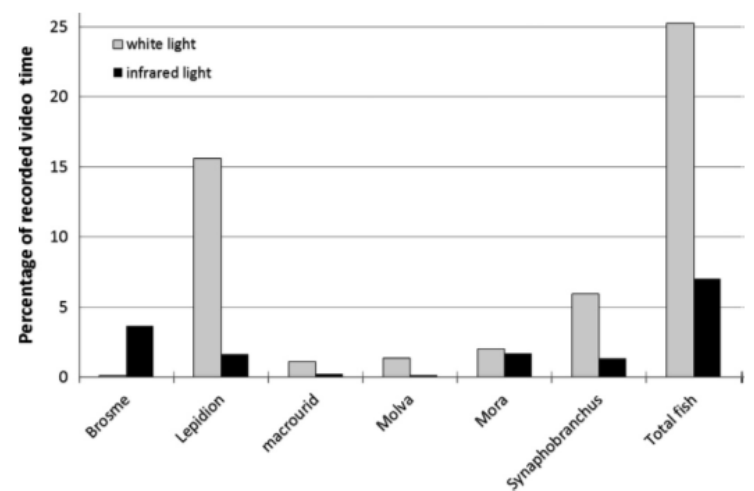

Fig. 4 The mean percentage of time that different fish species were seen on video in white light (grey bar) and infrared light (black bar), respectively, relative to the total recorded video time in the two light conditions, during the Hatton Bank deployments with bait in 2008

\subsection{Second long-term deployment (Galway Mound 2010-2011)}

During the second long-term deployment (first failed) the video recordings of the baited carousel covered the period 23 September 2010-20 March 2011. A total of 7996 video clips of $17 \mathrm{~s}$ every $30 \mathrm{~min}$ were recorded (equally divided over both

camera's), however, in 459 instances the gap between recordings caused by a software bug was $1 \mathrm{~h}$, in 17 instances $1 \mathrm{~h} 30 \mathrm{~min}$, and in only 3 instances $2 \mathrm{~h}$.

On 2293 clips (29\% of the total number of clips) one or more animals were seen. Of each video clip of $17 \mathrm{~s}$ the number of individuals of each species was counted. Because the clips were quite short, the chance of an animal swimming multiple times in and out of vision during one video clip was consequently negligible. The counts of animal sightings were then cumulated for baited, nonbaited and the whole deployment period. The most common scavengers were Amphipoda (2753x, number of animal sightings for the whole deployment period), but their presence was largely restricted to the first 2 months. The second most common scavenger was the red crab Chaceon affinis (1393x) (Fig. 7D-F), followed by NorthAtlantic codling L. eques (796x) (Fig. 7A) and the swimming crab Bathynectes maravigna (236x). Other scavengers recorded were the shrimp Atlantopandalus propinqvus (125x), the cushion starfish Porania pulvillus (61x), Euphausidae (55x), Calliostoma spec. (38x), other fishes (17x) including Mora moro, Phycis blennoides (Fig. 7B), Macrouridae, Gaidropsarus cf. vulgaris and a small shark, and the carrier crab Paromola cuvieri (1x) (Fig. 7C). It is obvious from Fig. 5 that the bait attracted more scavengers than the periods without bait, even though the baited period was almost two times shorter. The number of clips with one or more scavengers shows a zigzag pattern over time with dips during non-bait period (Fig. 5 A). This pattern is even more evident for the number of $C$. affinis sightings (Fig. 5B). However, scavengers are also present during non-bait periods, particularly the fish $\mathrm{L}$. eques and the crabs $B$. maravigna and $C$. affinis. Next to the bait the frame as a 3D structure seems to have also an attractiveness as a residential or hiding place for animals.

\subsubsection{Amphipoda}

During exposure of the first bait amphipods were the first to arrive i.e. within half an hour the vial opened. Peak numbers of 80 amphipods per clip were counted $5 \mathrm{~h}$ after bait exposure (Fig 7F). Numbers of amphipods declined rapidly, and after $30 \mathrm{~h}$ hardly any amphipods were seen (Fig. 6A). During the second bait exposure more or less the same pattern was seen but numbers were lower and were extended over a longer time period. A peak number ( 35 per clip) of amphipods was reached after $28 \mathrm{~h}$. After 3.5 days hardly any amphipods were seen and numbers remained low during subsequent bait exposures

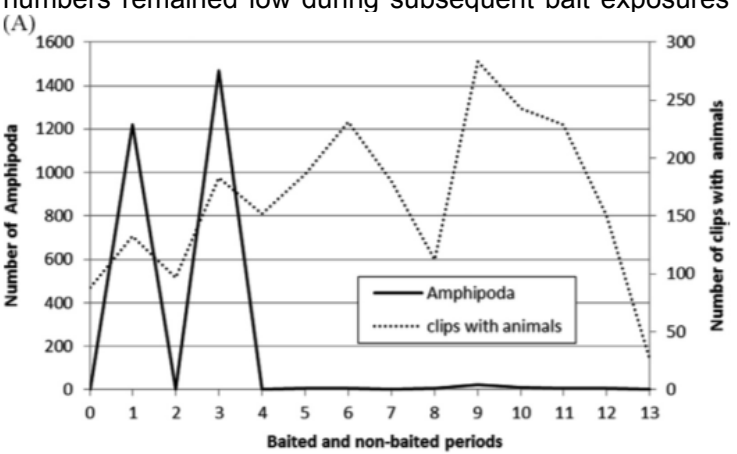

(B)

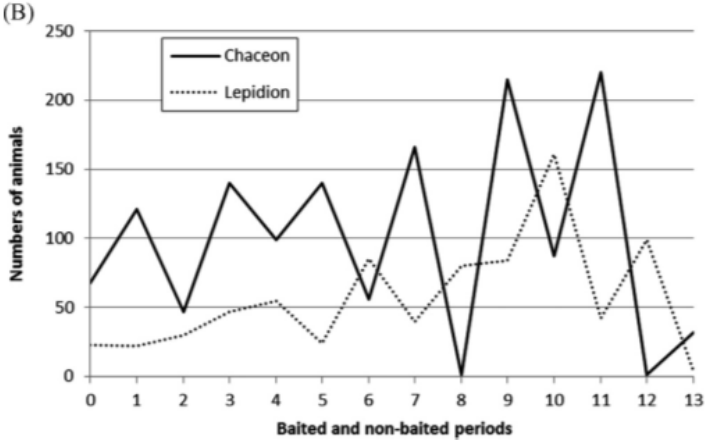

Fig. 5 Long-term deployment 2 (23 Sept. 2010-20 March 2011). Numbers of animals seen during the different baited and non-baited periods. Even numbers on the $x$-axis are non-bait periods, while odd numbers mean that bait is exposed. (A) The number of video clips per period in which one or more scavengers were seen (the maximum for a 10 day baited period would be 480 ), and the total number of amphipods seen per period. (B) Total number of sightings $\mathrm{C}$. affinis and $\mathrm{L}$. eques per period.

(Fig. 6B). As occasional amphipods were seen during the remaining deployment time, we assumed that the bait had lost its attractiveness to amphipods after 2 months. It was further noticed that during the two peaks in amphipod abundance, their numbers fluctuated with the current speed. During low current periods their numbers were high, while during high current periods they were almost absent. This fluctuation is clearly shown in Fig. 6A (2 peaks with a distance of $\sim 24 \mathrm{~h}$ ) and Fig. 6B (4 peaks also with a difference of $\sim 24 \mathrm{~h}$ ).

\subsubsection{Chaceon affinis}

The total number of sightings of the red crab $C$. affinis was always higher during a bait exposure than during the non-baited periods (Fig. 5B). During the deployment, total sightings per baited period of $C$. affinis increased from 121 during the first bait exposure to 220 during the 6th bait exposure. The crabs were clearly attracted by the bait, and were frequently seen their claw sticking in the bait vial, or using their longer walking legs when they could not reach the bait with their claw (Fig. 7F). In contrast to amphipods all 6 bait exposures attracted red crabs. The number of $C$. affinis eating from the bait showed two peaks during the end of December 2010 (30 sightings of crabs eating, $21 \%$ of total crab sightings in that period) and the end of January 2011 (49 sightings of crabs eating, $23 \%$ of total crab sightings in that period) (Fig. 8). Even in the last bait exposure which lasted only 3 days a red crab was seen eating from the bait. Occasionally other scavengers were seen eating from the bait, viz. A. propinqvus during periods $7(5 x), 9(22 x)$ and $11(6 x)$. The starfish $P$. pulvillus covered the opening of the baited vial for more than $9 \mathrm{~h}$ during period 5 until it was removed by a crab. So we conclude that bait did not lose its attractiveness for crabs, shrimps and Porania. 

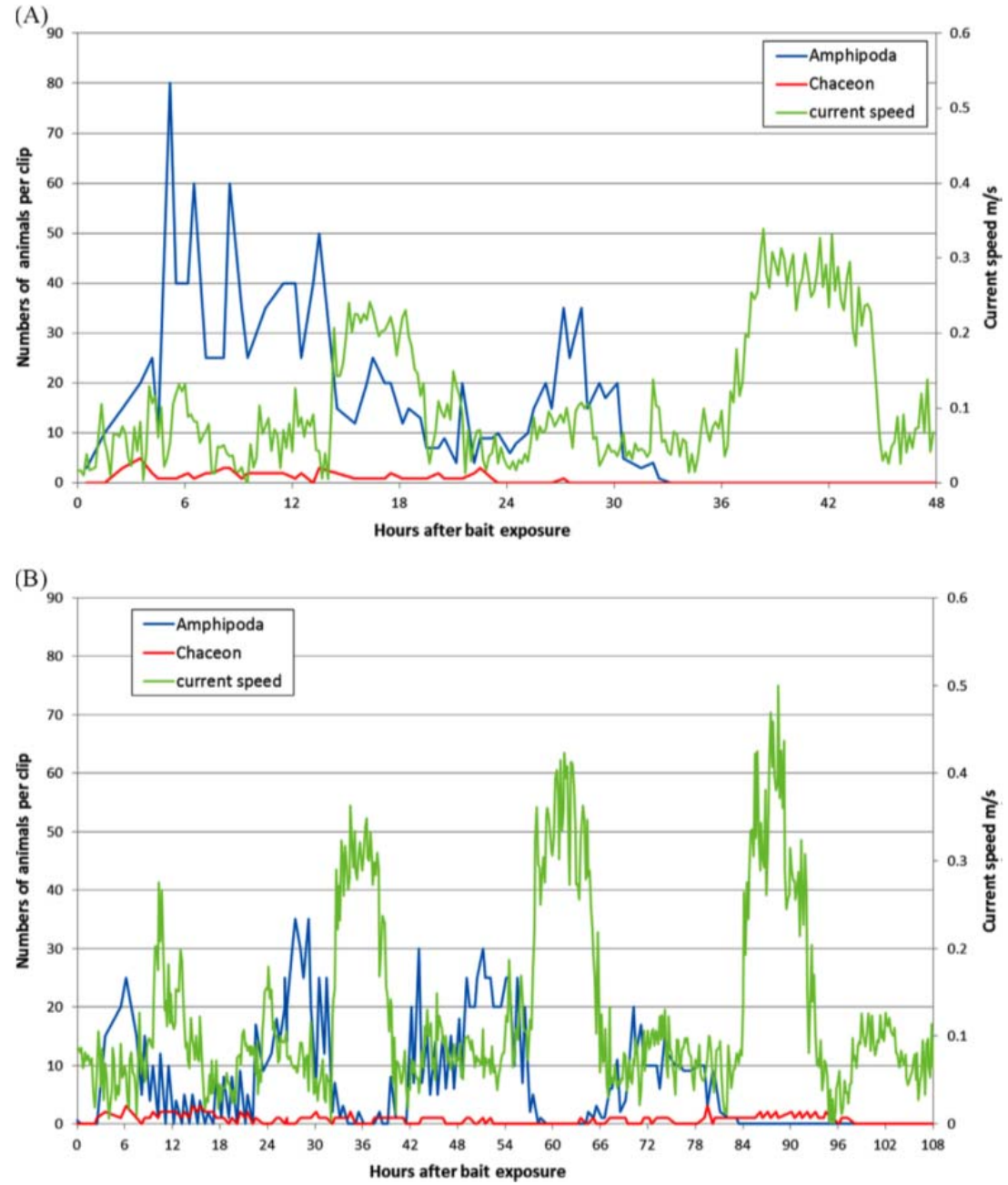

Fig. 6 Long-term deployment 2. Number of amphipods and C. affinis in each video clip over time. (A) During the first 2 days after exposure of the first bait. (B) During the first 4.5 days after exposure of the second bait. Current speed is shown in green (For interpretation of the references to color in this figure legend, the reader is referred to the web version of this article.

\subsubsection{Fishes}

The number of fish species recorded on the video was low (6 species), almost all fish were $L$. eques, and only $2 \%$ of fish sightings consisted of other species. Though $L$. eques was seen a number of times with its nose or chin barbel in the bait vial, it was never seen trying to reach the bait. The number of sightings of $L$. eques increased from 22 during the first bait exposure to 161 in the non-bait period 10, after which numbers decreased again. Surprisingly the number of sightings during a bait exposure was invariably lower than during one of the adjoining non-bait periods and in $50 \%$ of the cases lower than both adjacent non-bait periods (Fig. 5B). Though there was no clear avoidance or aggressiveness between $L$. eques and $C$. affinis seen on the video clips, the higher numbers of the red crab during baited periods could have influenced the numbers of $L$. eques negatively. We conclude that $L$. eques is more attracted by the frame than by the bait, and although we saw different individuals, this species is believed to be patrolling the area regularly. Uiblein et al. (2003) also characterise the behaviour of this species as "station holding". All other fish seen by us did not show a clear reaction to the bait. Jamieson et al. (2006) describe that structures on the deep-sea floor can have implications on fish behaviour, in their case on the macrourid Coryphaenoides armatus, which was much more attracted to the structure than to the bait. As our lander system forms a clear though open structure at the sea bottom it could have influenced the number of fish too.

\subsection{Third long-term deployment (Galway Mound 2011-2012)}

During the third deployment covering the period 5 October 2011-5 October 2012 a total of 7513 video clips were recorded (camera 1: 3826; camera 2: 3687) of the scheduled 7981 video clips. The missing clips were caused by an unsolved bug in the software, however, most of the times only one clip in sequence was lost which extended the gap between recordings to $2 \mathrm{~h} 12 \mathrm{~min}$. In 23 cases there was a larger gap of $3 \mathrm{~h} 18 \mathrm{~min}$, and in only 2 cases there was gap $4 \mathrm{~h} 24 \mathrm{~min}$.

The number of clips with one or more scavengers declined with time from a maximum of 208 during the first bait exposure to a minimum of 43 during bait exposure 22 (Fig. 9A). This is in contrast with the second long-term deployment where the sightings of animals during the baited periods increased in the first 5 months from 132 to 283 . The most common scavengers in the third deployment were Amphipoda (6665 sightings), but their presence largely restricted to the first 4.5 months. The second most common scavenger was the red crab C. affinis (962x), followed by the swimming crab B. maravigna (627x), and the North-Atlantic codling $L$. eques (280x). Other animals recorded were the Greater Forkbeard $P$. blennoides $(154 \mathrm{x})$, the shrimp $A$. propinqvus $(152 \mathrm{x})$, the carrier crab Paromola cuvieri (74x), Euphausidae (57x), and other fishes (123x) including Gaidropsarus cf. vulgaris (70x), Macrouridae (14x), M. moro (3x), Neocyttus helgae $(1 \mathrm{x})$, a ray $(1 \mathrm{x})$ and unidentified fish $(45 \mathrm{x}$, only shadow or 
(A)

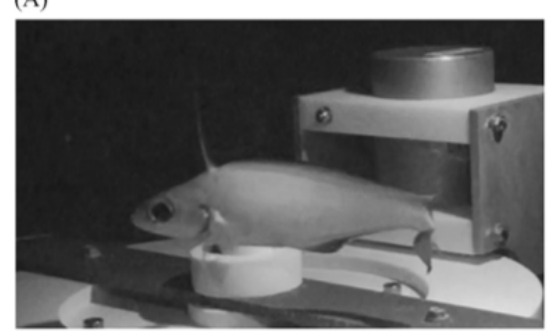

(C)

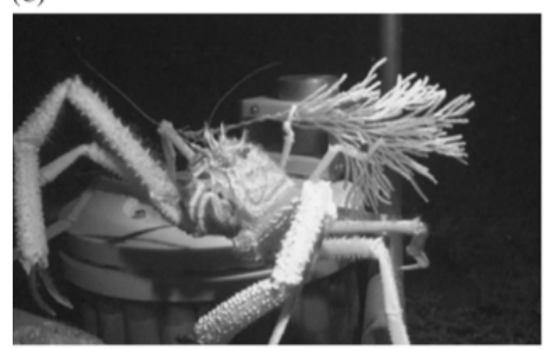

(E)

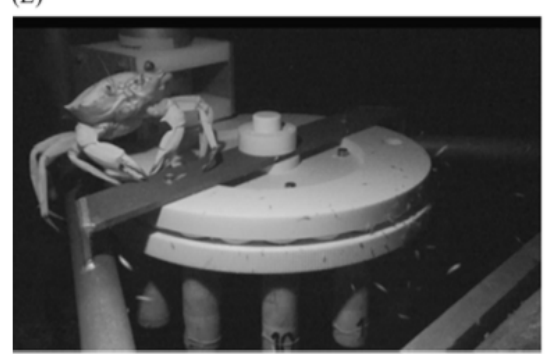

(B)

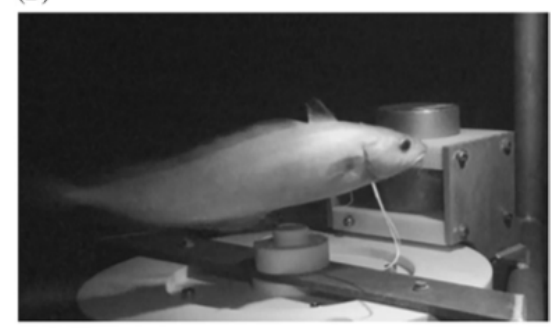

(D)

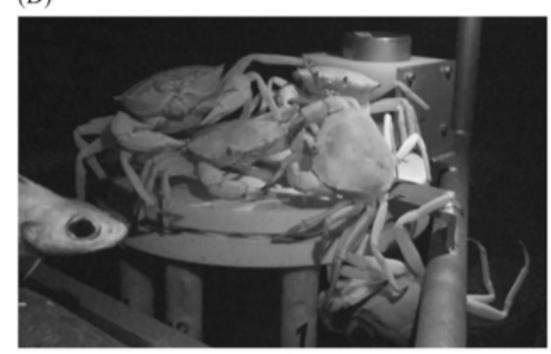

(F)

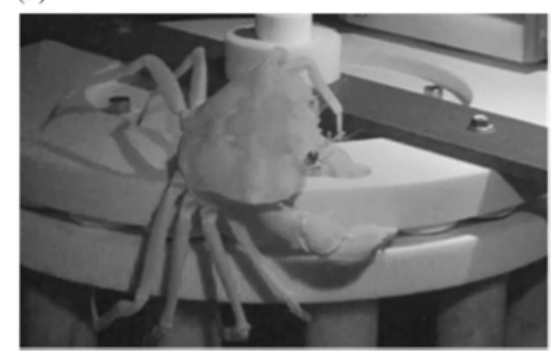

Fig. 7 Examples of animals attracted by the bait during the second long-term (Please insert Fig. 7 in the text after Fig. 6.) deployment. (A) Lepidion eques, (B) Phycis blennoides, (C) Paromola cuvieri, (D) Chaceon affinis (5x) and head of L. eques, (E) Peak of amphipod numbers (80x) and one C. affinis; picture taken by the second blennoides, (C) Paromola cuvieri, (D) Chaceon affinis (5x)
camera, (F) C. affinis with one claw deep into the bait vial.

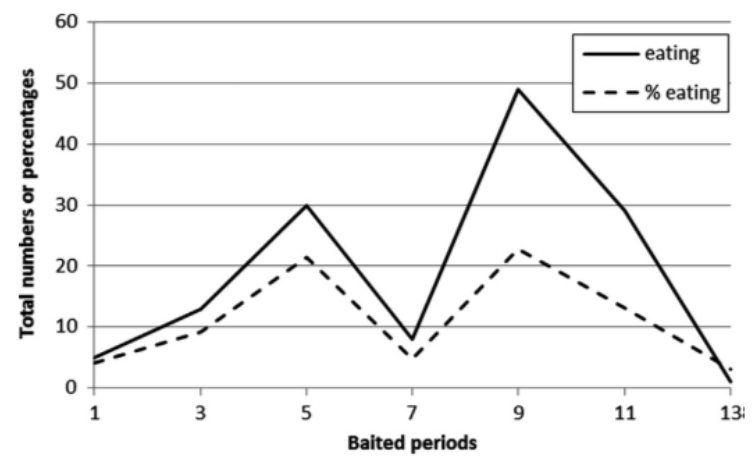

Fig. 8 Long-term deployment 2 . The number of times that crabs were actually seen eating from the bait during each period when bait was offered, also expressed as percentage of the total number of crab sightings during each period.

part seen). The bait seemed still attractive to at least some scavengers till the end of the experiment as indicated by crabs which were still actively eating from the bait. Apart from amphipods and red crabs, P. cuvieri, B. maravigna and $A$. propinqvus were the only other animals observed eating from the bait.

\subsubsection{Amphipoda}

The most abundant scavengers were amphipods (up to 1 $\mathrm{cm}$ ). They were often seen swimming fast in a straight horizontal line towards the bait at $10-30 \mathrm{~cm}$ above it, passing it by less than half a metre, and noticing the odour disappeared, turning around in an instant and without any hesitation disappearing into the open vial with bait. High numbers from 446 to 1231 (total numbers of sightings per exposure period) were seen in the first 9 bait exposure periods, i.e. during the first 4.5 months, with the exception of period 7 which had a low number of 35 amphipod sightings (Fig 9A). The absence of bait due to loss of vials 4 and 5 had no effect on the amphipod numbers. In fact, the highest numbers of amphipod sightings occurred during period 4 , while period 5 also had a very high number of 983 . After period 9 the numbers of amphipods dropped dramatically with roughly a factor 10 (maximum $45)$, and after period 17 hardly any amphipods were seen anymore (only in period 20 and 21 with respectively 2 and 4 amphipods). Especially during the first months amphipods were also seen sitting on the O-rings of the vials that were still closed, suggesting there was some leakage of odour there. This would also explain the high numbers of amphipods during period 4 and 5 when no bait was available.

\subsubsection{Crabs}

Large invertebrate scavengers attracted by the bait were the crabs $C$. affinis, B. maravigna and Paromola cuvieri, with the red crab $C$. affinis being the most frequent visitor. A total of 962 sightings of $C$. affinis were recorded over the whole deployment period, with an average of 40.1 per period (SD 28.3). All periods had at least one sighting of $C$. affinis, except for period 25 when no bait was offered anymore and which lasted only 6 days and was ended by the recovery of the lander. The number of sightings per bait exposure fluctuated strongly (Fig. 9D), with the highest numbers in period $1(72 x), 5(94 x)$ and $11(111 x)$, indicating that there was no clear decline in the sightings at least up to period 18. After that period the sightings did not reach the average number of sightings per bait period (40x) anymore, with a maximum of $25 x$ in period 23 , and a minimum of 1 in period 22. Striking was the high number of sightings during period 5 (no bait), and the low numbers during period 9 and 10 (respectively $5 x$ and $15 x$ ) before the maximum in period 11. Most of the times only one $C$. 

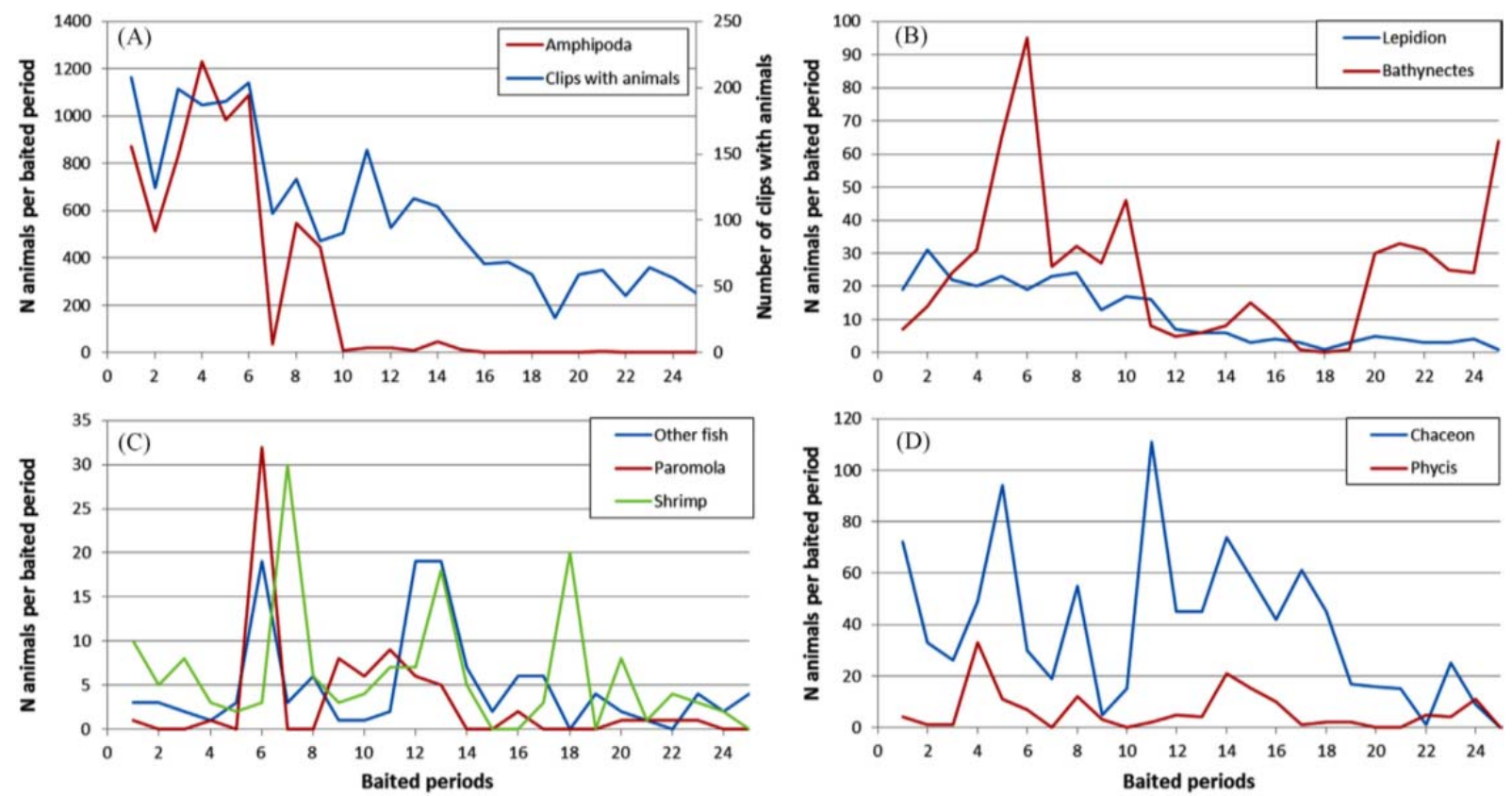

Fig. 9 Third long-term deployment. Numbers of animal sighting during each of the 24 exposures of bait. (A) The number of clips that one or more scavengers were seen, and the total number of amphipod sightings. (B) Total number of sightings of $B$. maravigna and $L$. eques. (C) The total number of sightings of other fish, $P$. cuvieri and $A$. propinquus (shrimp). (D) The total number of sightings $C$. affinis and $P$. blennoides.

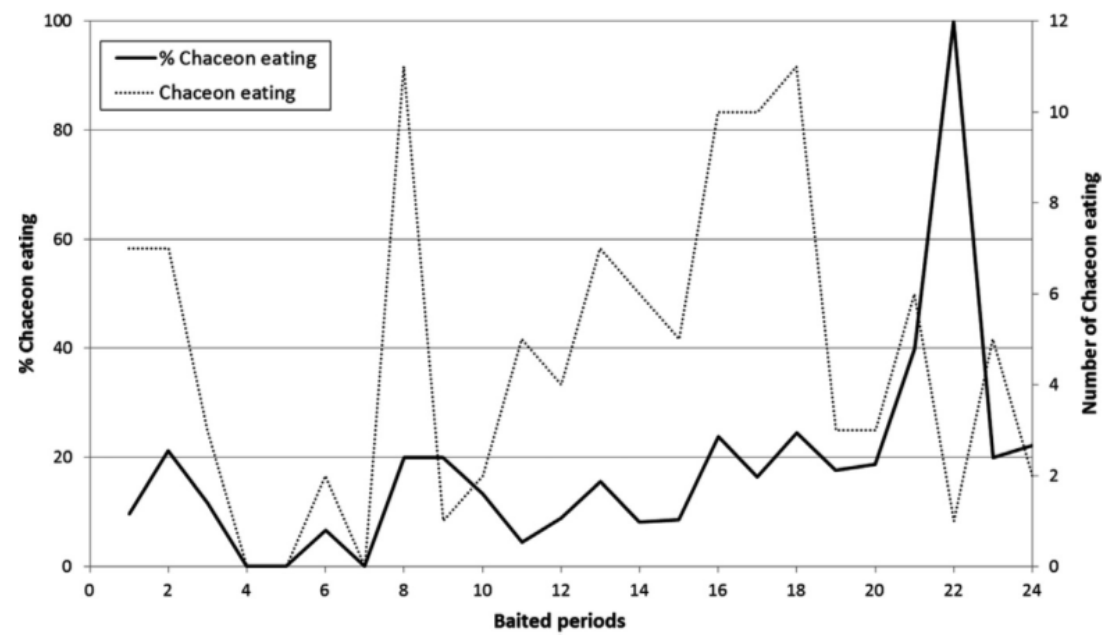

Fig. 10 Third long-term deployment. The total number of sightings of $C$. affinis actually eating from the bait during the 24 exposure periods (vial 4 and 5 had no bait), and expressed as the percentage of the total number of sightings of $C$. affinis during the separate baited periods.

affinis was seen at the bait $(94 \%)$, sometimes $2(6 \%)$, and only in three cases with 3 at or near the bait. The numbers of $C$. affinis that were actively eating from the bait (including having a claw or leg in the baited vial) did not decline clearly during the deployment (Fig. 10). A relation between the number of sightings and crabs actively eating is also not obvious (Fig. 10). The 100\% eaters in period 22 is caused by the fact that only one animal was seen in that period.

When a new bait vial had opened the number of C. affinis sightings per day was on average higher during the first 2 days than the remaining 13 days that the bait was available (Fig. 11). Juveniles crabs with a carapace width less than $5 \mathrm{~cm}$ were only seen in the period 11-14.

Apart from $C$. affinis the only other crabs seen were the large carrier crab, Paromola cuvieri, and the small swimming crab $B$. maravigna. $P$. cuvieri was recorded irregularly spread over the whole period, with a peak of 32 sightings in period 6 (Fig. 9C). This large carrier crab was seen actively eating from the bait, and never more than one specimen at a time. $B$. maravigna was quite common (627 sightings) spread over the whole period, but with a clear dip during period 12-20 (Fig. 9B). Though it was seen actively eating from the bait, most of the times it used the lander as a residence, and was often hiding in the housing of the motor of the carousel. During 40 recordings 2 specimen were seen at the same time, but never more.

\subsubsection{Fishes}

The most common fish recorded were $L$. eques (280 sightings), $P$. blennoides $(154 \mathrm{x})$, the rockling Gaidropsaurus cf. vulgaris (67x) and Macrouridae (14x). The rockling used the motor housing often as a residence, and was never really seen near the opening of the baited vial. The macrourids seemed to be attracted by the amphipods near the bait, and once seen eating them (period 3). L. eques was mostly passing by, but in 10 sightings it was directly above the bait opening with 3 times poking its nose in the vial opening. Twice it attacked a B. maravigna, and 4 times it was seen eating or snapping at amphipods. The amount of sightings per bait exposure of $L$. eques gradually dropped over time, without clear fluctuations, from a maximum of 31 in period 2 , to 5 or less in periods 15 to 24 (Fig. 9B). Only once 2 


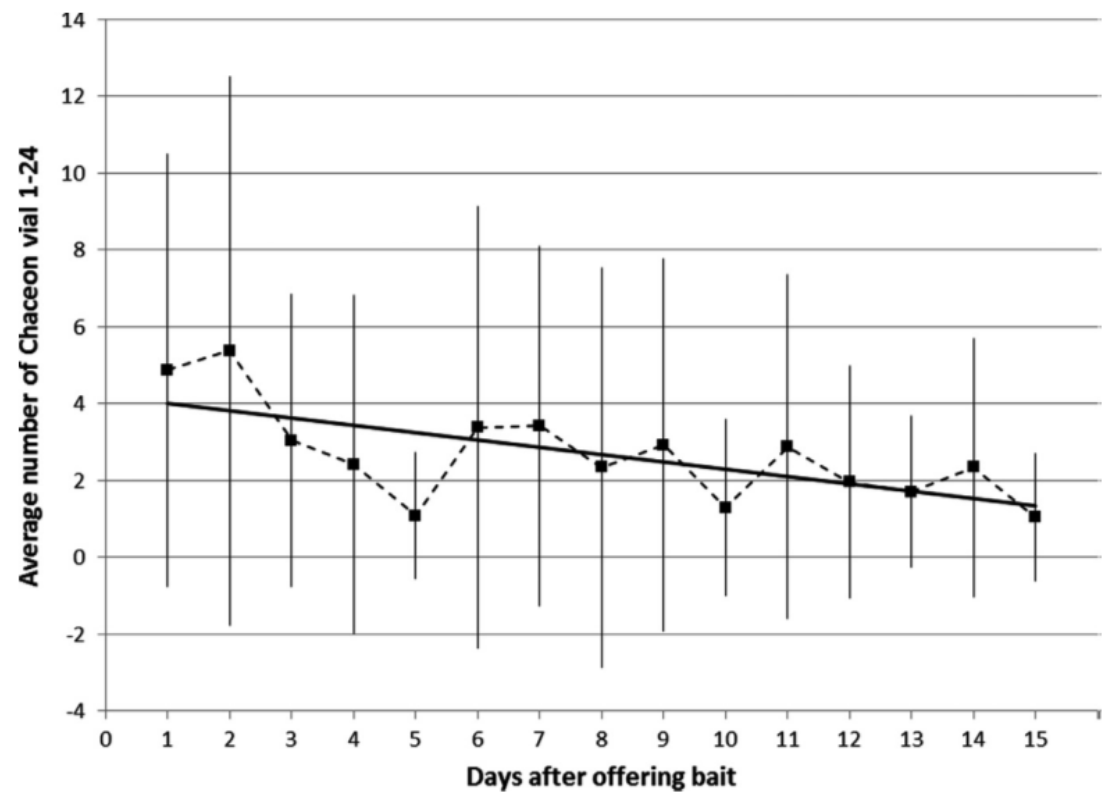

Fig. 11 Third long-term deployment. Average number of sightings of $C$. affinis for baited vial 1 to 24 on each day of the 15 days exposure time of the bait. A standard Fig. 11 Third long-term deployment. Average number
deviation is show, and a trendline has been added.

specimens were seen at the same time. The forkbeard, $P$. blennoides, was mostly seen swimming near the frame or above the carousel and seemed primarily interested in the amphipods which it was seen eating in 6 clips. On only 2 occasions $P$. blennoides showed interest in the opening of the bait vial. Mostly only one specimen of $P$. blennoides was seen in a video clip, only twice 2 specimens and twice a specimen of $L$. eques together with $P$. blennoides

\section{Conclusion}

\subsection{Experimental design}

On the basis of preliminary results obtained during the pilot at Hatton Bank plus literature data we decided to proceed with development of the infrared light source shown in Fig. 1 despite the absence of statistical rigour in our data due to logistic limitations. Our choice for infrared light at that time was supported by studies by Widder et al. (2005) and Raymond and Widder (2007) showing deep-sea fish can be attracted or repelled by white light, while they seem to be indifferent to infrared light. The explanation is that most fish have a single visual pigment, of which the maximum sensitivity lies in the bluegreen region of the visible light. Therefore light with longer wavelengths, such as red $(685 \mathrm{~nm})$, far-red $(695 \mathrm{~nm})$ or infra-red $(>700 \mathrm{~nm})$, is less visible for fish or not visible at all. More recently Bassett and Montgomery (2011) and Harvey et al. (2012) used (infra)red light for the same reason in a study of nocturnal fish in shallow water.

One of the biggest problems we were faced with is the choice of bait that can be kept for longer periods without decay to ensure constant attractiveness. For their 36 day deployment Kemp et al. (2008) used intact fresh mackerel which has been used as 'bait of choice' in most deep-sea baited camera drops done by Oceanlab (e.g. Bailey et al., 2007) and others including present authors. The advantage of a standardized bait is comparability among deployments and users. However, having to deal with 12 or 24 containers with mackerel in our case is a technical challenge. Importantly, the issue with keeping the bait of constant quality had not been solved by Kemp et al. (2008) despite the fact that their experiment was performed at comparatively lower temperature $\left(4{ }^{\circ} \mathrm{C}\right)$ and higher pressure $(3664 \mathrm{~m})$ which they assumed would preserve the bait over time. Our choice for sardines in oil solved the preservation issue but a comparison between attractiveness of sardines and mackerel for instance in terms of first approach time of scavengers, still has to be made to be able to compare earlier data.

\subsection{Temporal patterns and seasonality}

The decreasing numbers of amphipods during the third long-term deployment in our view does not point to seasonality. Similarly as in the second long-term deployment, the bait lost its attractiveness specifically for amphipods quite rapidly during the first bait exposures and in the course of the whole deployment suggesting that amphipods are only attracted by "fresh" bait. The (minimal) decay of bait in oil in the closed vials at an ambient temperature of $8-11^{\circ} \mathrm{C}$ was probably enough to lose its attractiveness for amphipods. The presence of dead conspecifics trapped in the first vials after their exposure could have an effect on numbers since crustaceans including amphipods have been shown to avoid scent of injured or dead conspecifics (Wisenden et al., 2001; Aggio and Derby 2011). We consider this unlikely as the amphipods did not return at all in the later exposures, apart from a few specimens swimming-by. Overfeeding of amphipods does not seem to be an explanation either, as the bait was offered in relatively small portions $(230 \mathrm{~g}$ wet weight), and ingestion rates by scavengers during different baited experiment by others were in the range of 1100 $2600 \mathrm{~g} \mathrm{~d}-1$ (Sweetman et al., 2014). Besides, in the second long-term deployment the baited period was interrupted after 10 days with a 18 day non-bait period, which would be enough time for digestion. Noticeable was that current speed influenced the number of amphipods. A high current did not attract a larger number of amphipods by spreading the odour over a larger area, but instead periods with higher currents $(>10 \mathrm{~cm} / \mathrm{s})$ showed decreasing numbers of amphipods with values often reaching zero when currents increased above $25 \mathrm{~cm} / \mathrm{s}$ (Fig 6). Recorded swimming speeds for scavenging (lyssianassoid) amphipods in the deep-sea are between 2 and $12 \mathrm{~cm} / \mathrm{s}$ with burst speeds up to $25 \mathrm{~cm} / \mathrm{s}$ (Jamieson et al. 2012) and with an practical average of $5 \mathrm{~cm} / \mathrm{s}$ (SainteMarie and Hargrave (1987). Apparently currents above 10 $\mathrm{cm} / \mathrm{s}$ are becoming a problem for amphipods to swim against it. We do not have an explanation for the decrease of sightings in time of the codling $L$. eques during the third deployment, or for the increase in sightings in the second deployment. Since the two deployments show opposing 
trends in $L$. eques over the same period of the year, seasonality can be excluded. Because $L$. eques showed little affiliation with the bait itself, we assume that the species is not suited to be studied with the bait system we used or perhaps even baited cameras in general (see Priede et al., 1994)

For B. maravigna, C. affinis and P. blennoides there were indications for seasonality. For $B$. maravigna (Fig. 9B) there are two periods were it is quite abundant, namely period 4 to 10 (end of November to early March) and period 20-24 (half July to end of September). However, data are heavily influenced by the fact that individuals stay for longer periods on the frame. The distribution of $P$. blennoides over time is quite irregular over time, with peaks in sightings in period 4-5, 8, 14-16 and 24. Though $P$. blennoides has lower numbers of sightings, the pattern is somewhat comparable with that of $B$. maravigna (Fig. 9B and D). For C. affinis the distribution pattern is irregular over time, but periods $1-8$ and 11-18 had a relatively high average number of sightings per baited period, i.e. 47 and 60 , respectively. This is in contrast to the period 9-10 (average 10) and 19-24 (average 14) when abundance was much lower. If we assume that $C$. affinis is similar in its behaviour to the related deep-water species of the NW Atlantic, Chaceon quinquedens (Steimle et al., 2001), then it does not stop feeding during the reproduction time as most other crabs do. Hence reproduction would not be the cause for the dips in its occurrence. Besides, a clear seasonality in reproduction has not been established for $C$. quinquedens (Steimle et al. 2001). Tagging studies showed that $\mathrm{C}$. quinquedens moved up and down the slope covering a range of $500 \mathrm{~m}$ depth difference and distances of up to 20 $\mathrm{km}$ with a maximum of $100 \mathrm{~km}$ (Lux et al., 1982), but without clear seasonality. For $C$. affinis around the Canary Islands López Abellán et al. (2002) ascribed seasonal migration to reproduction, but also showed that its spawning period is extensive (October-May). The sighting of juveniles of this crab (carapace width $<5 \mathrm{~cm}$ ) in period 11-13 (3 Feb - 18 March) could indicate seasonality, but numbers are too low to corroborate this.

Although we did not find concrete evidence for seasonal patterns, our observations in the cold-water coral community at Galway Mound do show substantial temporal variation in the abundance of scavengers. This implies that single ad hoc short-term deployments may lead to errors in estimation of abundance and biomass of scavengers and for instance in their role in carbon cycling (van Oevelen et al., 2009). Moreover, the successful long-term deployments of our baited camera system opens the way to employ such a system for monitoring impacts of disturbances on the deep-sea floor caused by for instance deep-sea oil exploitation (Vardaro et al., 2013) or deep-sea mining (Van Dover, 2011). We infer that mobile scavengers relying on olfactory and other senses will be the first organisms to show a reaction to the chemically and physically (noise, vibrations) altered environment similar to the early warning of escaping gas provided by a canary in a coalmine.

\section{Acknowledgments}

Anthony Grehan (University Galway) and Tom Kennedy of the Fiona $\mathrm{K}$ II for their assistance in salvaging of the ALBEX lander that surfaced prematurely in 2012. Funding for M.L. and equipment came from the EUCoralFISH Project (EC contract number 213144) within the European Community 's Seventh Framework Programme (FP7/2007-2013). Royal NIOZ funded the shiptime for this study. The captain and crew of RV Pelagia and NIOZ technicians are acknowledged for their help with the field work.
References

Aggio, J., Derby, C.D., Chemical communication in lobsters, In: Breithaupt, T., Thiel, M T., (Eds.), Chemical Communication in Crustaceans, 2011, Springer Science+Business Media, 239-256.

Auster, P.J., Are deep-water corals important habitats for fishes, In: Freiwald, A., Roberts, J.M., (Eds.), ColdWater Corals and Ecosystems, 2005, Springer-Verlag; Berlin, Germany, 747-760.

Bailey, D.M., King, N.J., Priede, I.G., Cameras and carcasses: historical and current methods for using artificial food falls to study deep-water animals, Mar. Ecol. Prog. Ser. 350, 2007, 179-191.

Bassett, D.K., Montgomery, J.C., Investigating nocturnal fish populations in situ using baited underwater video: With special reference to their olfactory capabilities, J. Exp. Mar. Biol. Ecol. 409, 2011, 194-199.

Billett, D.S.M., Bett, B.J., Reid, W.D.K., Boorman, B., Priede, I.G., Long-term change in the abyssal NE Atlantic: The 'Amperima Event' revisited, Deep-Sea Res. Part II-Top. Stud. Oceanogr. 57, 2010, 14061417.

Buhl-Mortensen, L., Vanreusel, A., Gooday, A.J., Levin, L.A., Priede, I.G., Mortensen, P., Gheerardyn, H., King, N.J., Raes, M., Biological structures as a source of habitat heterogeneity and biodiversity on the deep ocean margins, Mar. Ecol. 31, 2010, 21-50.

Chidami, S., Guénard, G., Amyot, M., Underwater infrared video system for behavioral studies in lakes, Limnol. Oceanogr. Methods 5, 2007, 371-378.

Costello, M.J., McCrea, M., Freiwald, A., Lundälv, T., Jonsson, L., et al., Role of cold-water Lophelia pertusa coral reefs as fish habitat in the NE Atlantic, In: Freiwald, A., Roberts, J.M., (Eds.), Cold-water Corals and Ecosystems, 2005, Springer-Verlag; Berlin Heidelberg, 771-805.

Davies, A.J. Guinotte, J.M., Global habitat suitability for framework-forming cold-water corals, PLoS One 6 (4), 2011, 1-15.

D’Onghia, G., Maiorano, P., Sion, L., Giove, A., Capezzuto, F., et al., Effects of deep-water coral banks on the abundance and size structure of the megafauna in the Mediterranean Sea, Deep-Sea Res. Part II-Top. Stud. Oceanogr. 57, 2010, 397-411.

D'Onghia, G., Maiorano, P., Carlucci, R., Capezzuto, F., Carluccio, A., et al., Comparing deep-sea fish fauna between coral and non-coral "megahabitats" in the Santa Maria di Leuca cold-water coral province (Mediterranean Sea), PLoS One 7 (9), 2012, 1-16.

Doya, C., Aguzzi, J., Pardo, M., Matabos, M., Company, J.B., et al., Diel behavioral rhythms in sablefish (Anoplopoma fimbria) and other benthic species, as recorded by the Deep-sea cabled observatories in Barkley canyon (NEPTUNE-Canada), J. Mar. Syst. 130, 2014, 69-78.

Dunlop, K.M., Baited underwater camera studies of the biodiversity and abundance of animals in the temperate, tropical and Antarctic marine environment (Ph.D. thesis), 2013, Univ. Glasgow234.

Duineveld, G.C.A., Lavaleye, M.S.S., Bergman, M.J.N., De Stigter, H., Mienis, F., Trophic structure of a cold-water coral mound community (Rockall Bank, NE Atlantic) in relation to the near-bottom particle supply and current regime, Bull. Mar. Sci. 81, 2007, 449-467.

Foubert, A., Beck, T., Wheeler, A.J., Opderbecke, J. Grehan, A., Klages, M., Thiede, J., Henriet, J.-P., Polarstern ARK XIX/3a Shipboard Party, 2005. New view of the Belgica Mounds, Porcupine Seabight, NE Atlantic: preliminary results from the Polarstern ARKXIX/3a ROV cruise. In: Freiwald, A., Roberts, J.M., (Eds.). Cold-water corals and ecosystems, Erlangen Earth Conference Series, pp. 403-415. 
Harvey, E.S., Butler, J.J., McLean, D.L., Shand J., Contrasting habitat use of diurnal and nocturnal fish assemblages in temperate Western Australia, J. Exp. Mar. Biol. Ecol. 426-427 (2012), 2012, 78-86.

Henry, L.A., Roberts, J.M., Biodiversity and ecological composition of macrobenthos on cold-water coral mounds and adjacent off-mound habitat in the bathyal Porcupine Seabight, NE Atlantic, Deep-Sea Res. Part I-Oceanogr. Res. Pap. 54, 2007, 654-672.

Jamieson, A.J., Bailey, D.M., Wagner, H.-J., Bagley, P.M., Priede, I.G., Behavioural responses to structures on the seafloor by the deep-sea fish Coryphaenoides armatus: implications for the use of baited landers, Deep-Sea Res. Part I-Oceanogr. Res. Pap. 53, 2006, 1157-1166.

Jamieson, A.J., Lörz, A.-N., Fujii, T., Priede I.G., In situ observations of trophic behaviour and locomotion of Princaxelia amphipods (Crustacea: Pardaliscidae) at hadal depths in four West Pacific Trenches, J. Mar. Biol. Assoc. UK 92, 2012, 143-150.

Kemp, K.M., Jamieson, A.J., Bagley, P.M., Collins, M.A., Priede I.G., A new technique for periodic bait release at a deep-sea camera platform: first results from the Charlie-Gibbs Fracture Zone, Mid-Atlantic Ridge, Deep-Sea Res. Part II-Top. Stud. Oceanogr. 55, 2008, 218-228.

King, N.J., Bailey, D.M, Priede, I.G., Role of scavengers in marine ecosystems-introduction, Mar. Ecol. Prog. Ser. 350, 2007, 175--178.

Kutti, T., Bergstad, O.A., Fosså, J.-H., Helle, K., Coldwater coral mounds and sponge-beds as habitats for demersal fish on the Norwegian shelf, Deep-Sea Res. II-Top. Stud. Oceanogr. 99, 2014, 122-133.

López Abellán, L.J., Balguerıas, E., Fernández-Vergaz, V., Life history characteristics of the deep-sea crab Chaceon affinis population off Tenerife (Canary Islands), Fish. Res. 58, 2002, 231--2239.

Lux, F.E., Ganz, A.R., Rathjen, W.F., Marking studies on the red crab Geryon quinquedens Smith off southern New England, J. Shellfish Res. 2 (1), 1982, 71-80.

Martinez, I., Jones, E.G., Davie, S.L., Neat, F.C., Wigham, B.D., et al., Variability in behaviour of four fish species attracted to baited underwater cameras in the North Sea, Hydrobiologia 670, 2011, 23-34.

Matabos, M., Bui, A.O.V., Mihaly, S., Aguzzi, J., Juniper, S.K., et al., High-frequency study of epibenthic megafaunal community dynamics in Barkley Canyon: a multi-disciplinary approach using the NEPTUNE Canada network, J. Mar. Syst. 130, 2014, 56-68.

Merritt, D., Donovan, M.K., Kelley, C., Waterhouse, L., Parke, M., et al., BotCam: a baited camera system for nonextractive monitoring of bottomfish species, Fish. Bull. 109, 2011, 56-67.

Priede, I., Bagley, P., Smith, A., Creasey, S., Merrett, N., Scavenging deep demersal fishes of the Porcupine Seabight, North-east Atlantic: Observations by baited camera, trap and trawl, J. Mar. Biol. Assoc. United Kingd. Plymouth 74, 1994, 481-498.

Purser, A., Orejas, C., Gori, A., Tong, R.J., Unnithan, V., et al., Local variation in the distribution of benthic megafauna species associated with cold-water coral reefs on the Norwegian margin, Cont. Shelf Res. 54, 2013, 37-51.

Raymond E.H. and Widder E.A., Behavioral responses of two deep-sea fish species to red, far-red, and white light, Mar. Ecol. Prog. Ser. 350, 2007, 291-298.

Ruhl, H.A., Smith K.L., Shifts in deep-sea community structure linked to climate and food supply, Science 305, 2004, 513-515.

Sainte-Marie, B., Hargrave, B.T., Estimation of scavenger abundance and distance of attraction to bait, Mar. Biol. 94, 1987, 431-443.

Smith, CR, Glover, AG, Treude, T, Higgs, N.D., Amon D.J. Whale-fall ecosystems: Recent insights into ecology, paleoecology, and evolution, Ann. Rev. Mar. Sci. 7, 2015, 571-596.
Söffker, M., Sloman, K.A., Hall-Spencer, J.M., In situ observations of fish associated with coral reefs off Ireland, Deep-Sea Res. Part I-Oceanogr. Res. Pap. 58 2011, 818-825.

Steimle, F.W., Zetlin, C.A., Chanh, S., 2011. Red deep sea crab, Chaceon (Geryon) quinquedens, life history and habitat characteristics. NOAA technical memorandum NMFS-NE-163, pp. 1-27.

Sweetman, A.K., Smith, C.R., Dale, T., Jones, D.O.B., Rapid scavenging of jellyfish carcasses reveals the importance of gelatinous material to deep-sea food webs. Proc. R. Soc. B 281, 2014, 20142210.

Trenkel, V.M., Lorance, P., Mahevas, S., Do visual transects provide true population density estimates for deepwater fish?, ICES J. Mar. Sci. 61, 2004, 10501056.

Uiblein, F., Lorance, P., Latrouite, D., Behaviour and habitat utilisation of seven demersal fish species on the Bay of Biscay continental slope, NE Atlantic, Mar. Ecol. Prog. Ser. 257, 2003, 223-232.

Van Dover, C.L., Mining seafloor massive sulphides and biodiversity: what is at risk?, ICES J. Mar. Sci. 68, 2011, 341-348.

van Oevelen, D., Duineveld, G., Lavaleye, M., Mienis, F., Soetaert K., et al., The cold-water coral community as a hot spot for carbon cycling on continental margins: a food-web analysis from Rockall Bank (northeast Atlantic), Limnol. Oceanogr. 54, 2009, 1829-1844.

Vardaro, M.F., Bagley, P.M., Bailey, D.M., Bett, B.J., Jones, D.O.B., Milligan, R.J., Priede, I.G., Risien, C.M., Rowe, G.T., Ruhl, H.A., Sangolay, B.B., Smith, K.L., Walls, A., Clarke J., A southeast Atlantic deep-ocean observatory: first experiences and results, Limnol. Oceanogr.: Methods 11, 2013, 304-315.

Widder, E.A., Robison, B.H., Reisenbichler, K.R. and Haddock, S.H.D., Using red light for in situ observations of deep-sea fishes, Deep-Sea Res. 1 52, 2005, : 2077-: 2085.

Wisenden, B.D., Pohlman, S.G., Watkin, E.E., Avoidance of conspecific injury-released chemical cues by freeranging Gammarus lacustris (Crustacea: Amphipoda), J. Chem. Ecol. 27 (6), 2001, 1249-1257.

Witbaard, R., Duineveld, G.C.A., Kok, A., van der Weele, J., Berghuis, E.M., The response of Oneirophanta mutabilis (Holothuroidea) to the seasonal deposition of phytopigments at the porcupine Abyssal Plain in the Northeast Atlantic. Prog. Oceanogr.50,423-441. 